\title{
6. DATA REPORT: HIGH-RESOLUTION STUDY OF MAGNETIC PROPERTIES OF SAPROPEL-BEARING SEDIMENTS FROM SITES 966, 967, AND 969, EASTERN MEDITERRANEAN SEA ${ }^{1}$
}

\author{
Joseph S. Stoner, ${ }^{2}$ Carl Richter, ${ }^{3}$ and Andrew P. Roberts ${ }^{4}$
}

\begin{abstract}
High-resolution magnetic measurements were performed on sediments recovered from Sites 966, 967, and 969 during Leg 160 of the Ocean Drilling Program to the eastern Mediterranean Sea. Measurements of u-channel samples were made at 1-cm intervals from nearly complete composite stratigraphic sequences at each site. The measurements are integrated over stratigraphic intervals of $4.5 \mathrm{~cm}$, which allows high spatial resolution of sediment magnetic properties, including detailed characterization of variations in magnetic mineralogy, concentration, and grain size, as well as paleomagnetic determinations. We present u-channel magnetic data for more than $100 \mathrm{~m}$ of core from three eastern Mediterranean sites. Cyclic variations are observed over short and long stratigraphic intervals, which reflect variations in magnetic concentration and mineralogy of the sediments. The high-frequency variability is related to variations in nonsteady state diagenesis that results from cyclic deposition of organic-rich sapropels. This suggests that magnetic parameters may be an excellent proxy for diagenesis-related cyclicity in these sediments. Longer term changes may reflect significant variations in the climatic evolution of the eastern Mediterranean Sea.
\end{abstract}

\section{INTRODUCTION}

Extreme changes in environmental conditions in the eastern Mediterranean Sea are marked by organic carbon-rich sediment layers that are intercalated within lower Pliocene to Holocene hemipelagic marine sediments. These so-called sapropels have been used, along with carbonate cycles, to develop time series that have been tied to variations in the precessional index of the Earth's orbit, which has allowed development of a detailed Pliocene-Pleistocene time scale for marine sequences that now crop out above sea level in the Mediterranean region (Hilgen, 1991a, 1991b; Lourens et al., 1996). Sediments recovered during Ocean Drilling Program (ODP) Leg 160 preserve significantly more sapropels than are found in the land sections. In addition, other oxidized and/or bioturbated sapropels are often discernible only as "ghosts" in Leg 160 sediments (Emeis, Robertson, Richter, et al., 1996). Because of the significant differences in the number of sapropels that are preserved in different records and the difficulty in developing magnetic stratigraphies from Mediterranean marine sediments (Richter et al., Chap. 5, this volume), correlation between marine and on-shore sequences has had limited success.

A major finding of the shipboard paleomagnetic research during Leg 160 was that the sapropels are strongly magnetized relative to the surrounding sediments. Diagenetically reduced gray sediments that underlie the sapropels are typically extremely weakly magnetized, as would be expected if detrital magnetic grains in these sediments had been subjected to dissolution (Roberts et al., 1996, in press). Because magnetic properties may allow an increased understanding of sapropel diagenesis (Roberts et al., in press) and because they may provide a means of identifying oxidized sapropels that may not be easily distinguished using other means (van Santvoort et al., in press), a high-resolution study of $\mathrm{u}$-channel samples was undertaken to doc-

${ }^{1}$ Robertson, A.H.F., Emeis, K.-C., Richter, C., and Camerlenghi, A. (Eds.), 1998. Proc. ODP, Sci. Results, 160: College Station, TX (Ocean Drilling Program).

${ }^{2}$ Department of Geology, University of Florida, 1112 Turlington Hall, Gainesville, FL 32611, U.S.A. stoner@nervm.nerdc.ufl.edu

${ }^{3}$ Ocean Drilling Program, 1000 Discovery Drive, Texas A\&M Research Park, College Station, TX 77845-9547, U.S.A.

${ }^{4}$ Department of Oceanography, University of Southampton, Southampton Oceanography Centre, European Way, Southampton SO14 3ZH, United Kingdom. ument and identify the magnetic signature of sapropel- and nonsapropel-bearing intervals. Initial results of this study are reported here.

\section{METHODS}

Data were acquired from u-channel samples (Tauxe et al., 1983) that were measured on a narrow-access $2 \mathrm{G}$ Enterprises cryogenic magnetometer (Weeks et al., 1993; Nagy and Valet, 1993) at the University of California, Davis. U-channel samples are collected by pushing rigid, $\mathrm{u}$-shaped plastic liners $(2 \times 2 \mathrm{~cm}$ cross section, up to $1.5 \mathrm{~m}$ in length) into the archive halves of core sections. The sample is freed from the core by guiding a nylon fishing line under the $\mathrm{u}$ channel. A tightly fitting cap is then placed on the u-channel sample and the ends sealed to minimize dehydration of the sediment. Magnetic measurements on $\mathrm{u}$-channel samples were made at $1-\mathrm{cm}$ intervals; however, the half-width of the response function of the magnetometer pick-up coils $(4.5 \mathrm{~cm}$; Weeks et al., 1993) is such that adjacent measurements are not independent, and the data are smoothed over a $4.5-\mathrm{cm}$ measurement window. This smoothing is more than would occur in a continuous row of discrete samples; however, this disadvantage is offset by the decreased sediment deformation in uchannel samples and the significantly greater speed with which the measurements can be made (u-channel measurements are at least 20 times faster).

U-channel samples were taken from the archive halves of core sections from throughout the composite sequences of Sites 964, 966, and 967 and from Hole 969B. Because of time limitations for data processing, only data from Sites 966, 967, and 969 are reported here (see Tables 1-3, CD-ROM, back pocket, this volume). Before uchannel sampling, archive halves of core sections were measured aboard the JOIDES Resolution using a 2G Enterprises pass-through cryogenic magnetometer at $10-\mathrm{cm}$ intervals, after alternating field (AF) demagnetization at up to $25 \mathrm{mT}$. This wide-access magnetometer has a 15-cm smoothing window (Roberts et al., 1996). Because the archive halves had already been partially demagnetized, the natural remanent magnetization (NRM) was measured for all u-channel samples after AF demagnetization at 30, 40, 50, 60, and $70 \mathrm{mT}$ (Tables 1-3, CD-ROM, back pocket, this volume). An anhysteretic re- 
manent magnetization (ARM) was imparted using a 100 -mT peak field and a $0.05-\mathrm{mT}$ bias field, and then the sample was passed through the demagnetizer at a high-speed setting $(35.8 \mathrm{~cm} / \mathrm{s})$. ARM acquisition was subsequently found to be less efficient than when the track was operated at a slow speed $(0.4 \mathrm{~cm} / \mathrm{s})$. The high sample speed was found to impart an ARM that was generally equivalent to an ARM that was produced in a discrete sample with a peak field of about $60 \mathrm{mT}$ (in an appropriately adapted Schonstedt AF demagnetization unit). To maintain consistency throughout this study, all measurements were made on ARMs that were imparted using the highspeed setting. An isothermal remanent magnetization (IRM) was produced in a DC field of $1 \mathrm{~T}$ that was imparted by an in-line, long-core impulse magnetizer. The IRM acquired at $1 \mathrm{~T}$ is expressed as a saturation IRM (SIRM), despite the fact that canted antiferromagnetic grains may not be completely saturated at this field. Back-field IRMs that were imparted with DC fields of $-0.3 \mathrm{~T}\left(\mathrm{IRM}_{-0.3 \mathrm{~T}}\right)$ were used to obtain the $\mathrm{S}$ ratio $\left(\mathrm{S}_{-0.3 \mathrm{~T}}=\mathrm{IRM}_{-0.3 \mathrm{~T}} / \mathrm{SIRM}\right)$ and the "hard" IRM $\left(\mathrm{HIRM}_{-0.3 \mathrm{~T}}=\left(\mathrm{SIRM}+\mathrm{IRM}_{-0.3 \mathrm{~T}}\right) / 2\right) . \mathrm{S}$ ratio values $>1$ and HIRM values $<0$ were assumed to be the result of analytical error, possibly associated with magnetization of the tracking system and/or heterogeneities in the DC field generated by the inpulse magnetizer and were, therefore, set to 1 and 0 , respectively. A more detailed description of these parameters is given by King and Channell (1991).

U-channel and shipboard magnetic data are compared with volumetric magnetic susceptibility $(\mathrm{k})$ measurements that were made aboard the JOIDES Resolution. Magnetic susceptibility was measured at 3- to 5-cm intervals on whole-core sections after the cores had equilibrated to room temperature for $\sim 30 \mathrm{hr}$, using a Bartington Instruments MS-2 susceptibility meter with an 8-cm diameter sensing loop that induces a field of $0.1 \mathrm{mT}$ at a frequency of $470 \mathrm{~Hz}$. These data were interpolated to the 1-cm u-channel measurement interval to enable direct comparison of results.

Because our detailed magnetic studies have usually been conducted on composite stratigraphic sequences, the standard ODP meters below sea floor (mbsf) scale does not provide a useful way of presenting data. For each site, results are therefore presented with respect to the revised meters composite depth (rmcd) scale, which was established during detailed postcruise inter-core correlation work (Sakamoto et al., Chap. 4, this volume). Conversions back to the standard ODP meters below seafloor scale are straightforward (Sakamoto et al., Chap. 4, this volume).

\section{RESULTS}

High-resolution magnetic results from Sites 966, 967, and 969 contain evidence of cyclic variations in concentration-dependent parameters k, SIRM, ARM, and NRM (Figs. 1-3; Tables 1-3, CDROM, back pocket, this volume) and in constructed magnetic parameters ARM/k, SIRM/k, SIRM/ARM, $S_{-037}$ and HIRM (Figs. 4-6; Tables 1-3, CD-ROM, back pocket, this volume). These variations occur over both broad and extremely narrow stratigraphic intervals. The high-frequency, short-term variations are related to sudden changes in magnetic properties that are associated with diagenetic magnetic enhancements that are related to sapropel formation (Roberts et al., in press) and are most clearly evident in the ARM/k record at all three sites. These variations in both concentration-dependent and concentration-independent parameters suggest a complex magnetic signal that is associated with variation in concentration, grain size, and mineralogy of the magnetic assemblages. Detailed comparison with high-resolution geochemical data (e.g., Wehausen and Brumsack, Chap. 17, this volume) and lithology (e.g., Sakamoto et al., Chap. 4, this volume) will be needed for meaningful quantitative interpretation of the data. High-resolution magnetic studies from shipboard measurements across several sapropels suggest that large magnetic variations occur in the vicinity of sapropels (Roberts et al., in press). Comparison with the positions of sapropels, as documented in shipboard core descriptions (Emeis, Robertson, Richter, et al., 1996), suggest that some, but not all, of the observed variation can be explained by sapropel occurrences (Figs. 1-6). Similar variability is also observed in intervals where sapropels were not recognized and may suggest the former presence of sapropels that are now completely oxidized. Low-frequency cyclic variations in magnetic properties are also observed. These variations may reflect longer term changes in environmental conditions in the eastern Mediterranean Sea.

\section{ACKNOWLEDGMENTS}

We are grateful to members of the ODP Leg 160 shipboard scientific party for numerous discussions; Margaret Hastedt for providing outstanding technical support during Leg 160; Ken Verosub for the use of the long-core magnetometer; Akira Hayashida for his kind assistance and hospitality at the Department of Geology, University of California, Davis; and Will Sager for reviewing an earlier version of this manuscript. JSS, CR, and APR each gratefully acknowledge financial support from the U.S. Joint Oceanographic Institutions/U.S. Science Advisory Committee.

\section{REFERENCES}

Emeis, K.-C., Robertson, A.H.F., Richter, C., et al., 1996. Proc. ODP, Init. Repts., 160: College Station, TX (Ocean Drilling Program).

Hilgen, F.J., 1991a. Astronomical calibration of Gauss to Matuyama sapropels in the Mediterranean and implication for the geomagnetic polarity time scale. Earth Planet. Sci. Lett., 104:226-244.

, 1991b. Extension of the astronomically calibrated (polarity) time scale to the Miocene/Pliocene boundary. Earth Planet. Sci. Lett., 107:349-368.

King, J.W., and Channell, J.E.T., 1991. Sedimentary magnetism, environmental magnetism, and magnetostratigraphy. Rev. Geophys., Suppl., 29:358-370.

Lourens, L.J., Antonarakou, A., Hilgen, F.J., Van Hoof, A.A.M., VergnaudGrazzini, C., and Zachariasse, W.J., 1996. Evaluation of the Plio-Pleistocene astronomical timescale. Paleoceanography, 11:391-413.

Nagy, E.A., and Valet, J.-P., 1993. New advances for paleomagnetic studies of sediment cores using U-channels. Geophys. Res. Lett., 20:671-674.

Roberts, A.P., Stoner, J.S., and Richter, C., 1996. Coring induced magnetic overprints and limitations of the long-core paleomagnetic measurements technique: some observations from Leg 160, eastern Mediterranean Sea. In Emeis, K.-C., Robertson, A.H.F., Richter, C., et al., Proc. ODP, Init. Repts., 160: College Station, TX (Ocean Drilling Program), 497-505.

Roberts, A.P., Stoner, J.S., and Richter, C., in press. Diagenetic magnetic enhancement of sapropels from the eastern Mediterranean Sea. Marine Geology.

Tauxe, L., LaBrecque, J.L., Dodson, R., and Fuller, M., 1983. "U” channels - a new technique for paleomagnetic analysis of hydraulic piston cores. Eos, 64:219.

van Santvoort, P.J.M., de Lange, G.J., Langereis, C.G., and Dekkers, M. J., in press. Geochemical and mineral magnetic evidence for the occurrence of "missing" sapropels in eastern Mediterranean sediments. Paleoceanography.

Weeks, R.J., Laj, C., Endignoux, L., Fuller, M.D., Roberts, A.P., Manganne, R., Blanchard, E., and Goree, W., 1993. Improvements in long-core measurement techniques: applications in palaeomagnetism and palaeoceanography. Geophys. J. Int., 114:651-662.

Date of initial receipt: 15 January 1997

Date of acceptance: 22 June 1997

Ms 160SR-028 
A k

(SI)
B (Shipboard $25 \mathrm{mT}$ )
C NRM Intensity (u-channel $30 \mathrm{mT}$ )
$(\mathrm{A} / \mathrm{m})$

D

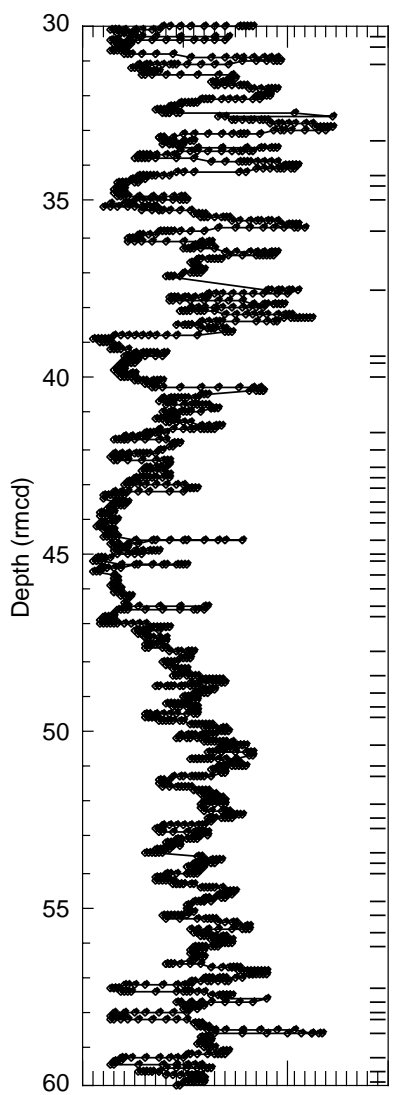

$\begin{array}{lll}0 & 0.01 & 0.02\end{array}$

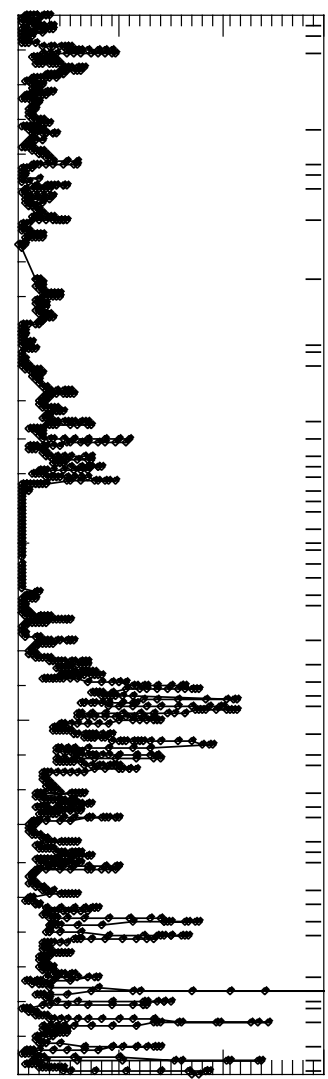
$\begin{array}{llll}0 & 0.25 & 0.5 & 0.75\end{array}$
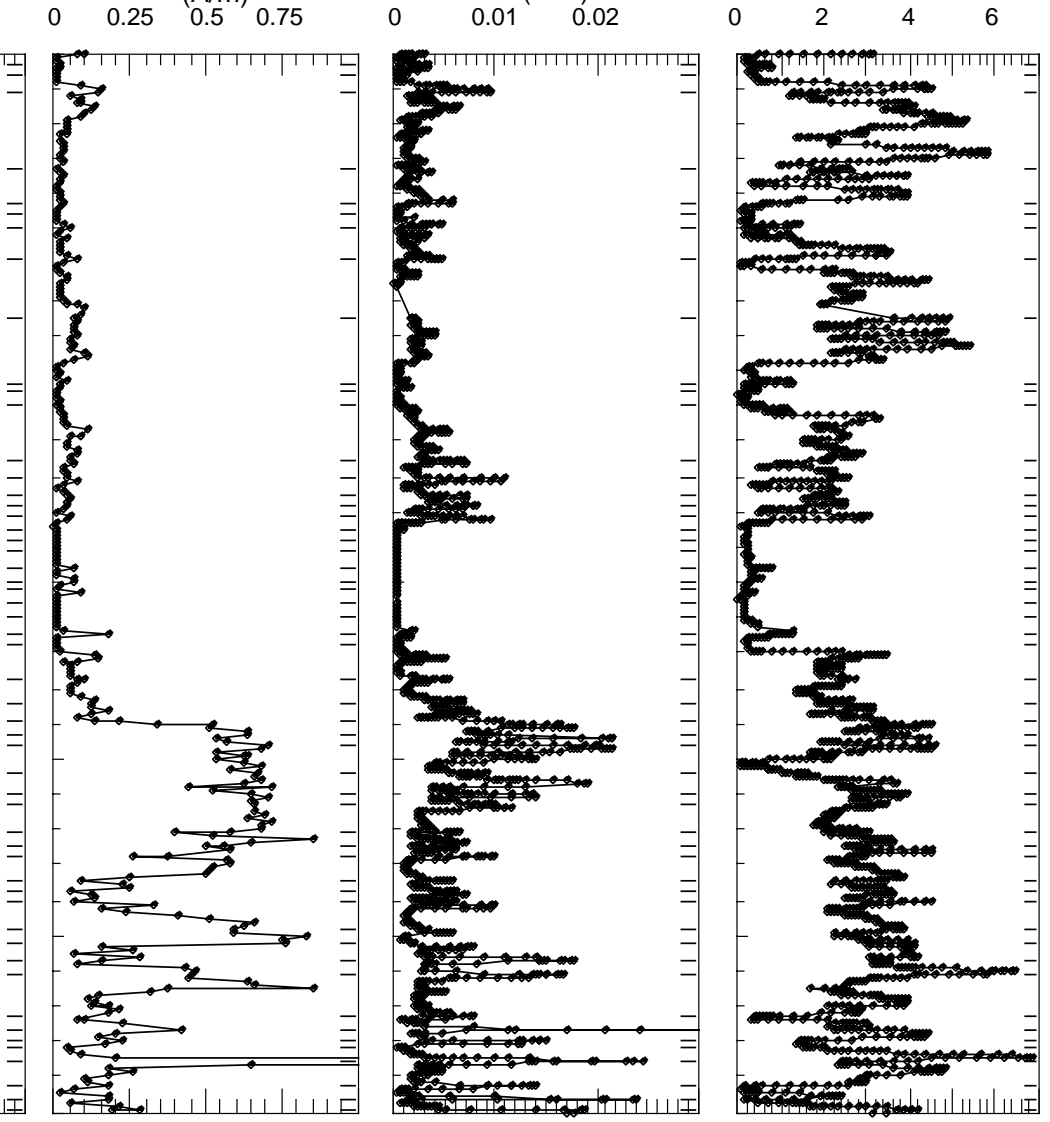

E

ARM

$(\mathrm{A} / \mathrm{m})$

Figure 1. Shipboard and u-channel magnetic measurements from the composite sequence for Site 966 for the interval from 30 to $60 \mathrm{rmcd}$. A. Volumetric magnetic susceptibility $(\mathrm{k})$ from shipboard measurements of whole cores, with interpolation to the same intervals as the corresponding u-channel measurements. B. Shipboard NRM intensity after AF demagnetization at $25 \mathrm{mT}$. C. NRM intensity after AF demagnetization at $30 \mathrm{mT}$ on u-channel samples. D. Saturation isothermal remanent magnetization (SIRM) from u-channel samples. E. Anhysteretic remanent magnetization (ARM) from u-channel samples. Horizontal bars on the right side of each figure indicate the position of sapropels, as identified from shipboard studies (Emeis, Robertson, Richter, et al., 1996). 
A

$\mathrm{k}$

(SI)
B NRM Intensity

$(\mathrm{A} / \mathrm{m})$

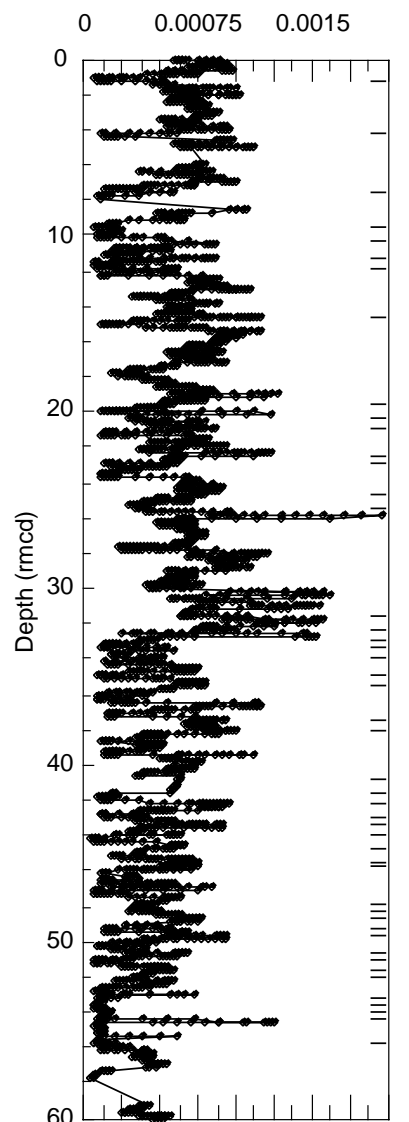

$0.02 \quad 0.04$

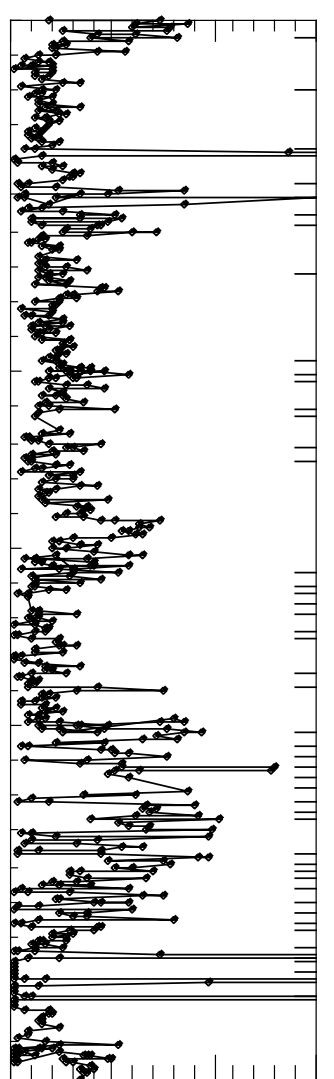

C NRM Intensity
(u-channel $30 \mathrm{mT})$ $(\mathrm{A} / \mathrm{m})$
D $\begin{aligned} & \text { SIRM } \\ & (\mathrm{A} / \mathrm{m})\end{aligned}$

0

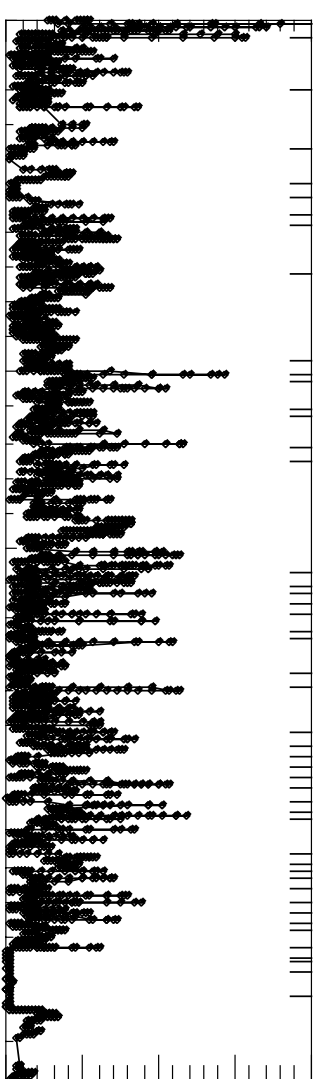

E

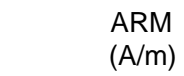

$\begin{array}{lllll}0 & 0.1 & 0.2 & 0.3 & 0.4\end{array}$
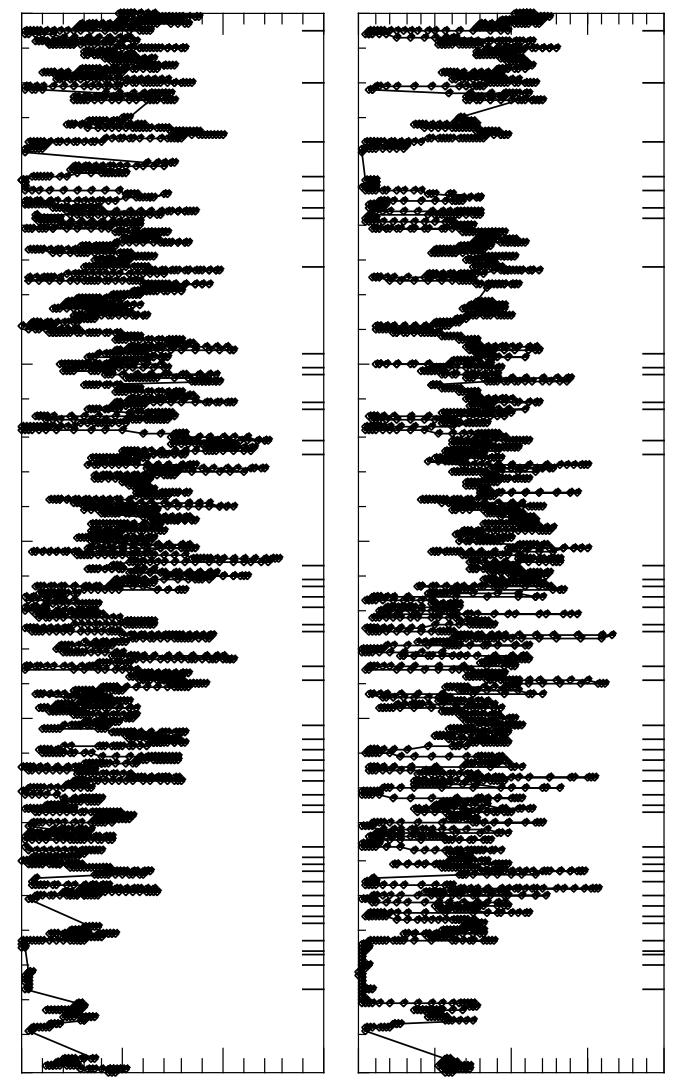

Figure 2. Shipboard and u-channel magnetic measurements from the composite sequence for Site 967 for the interval from 0 to $60 \mathrm{rmcd}$. Panels (A-E) are the same as for Figure 1. 


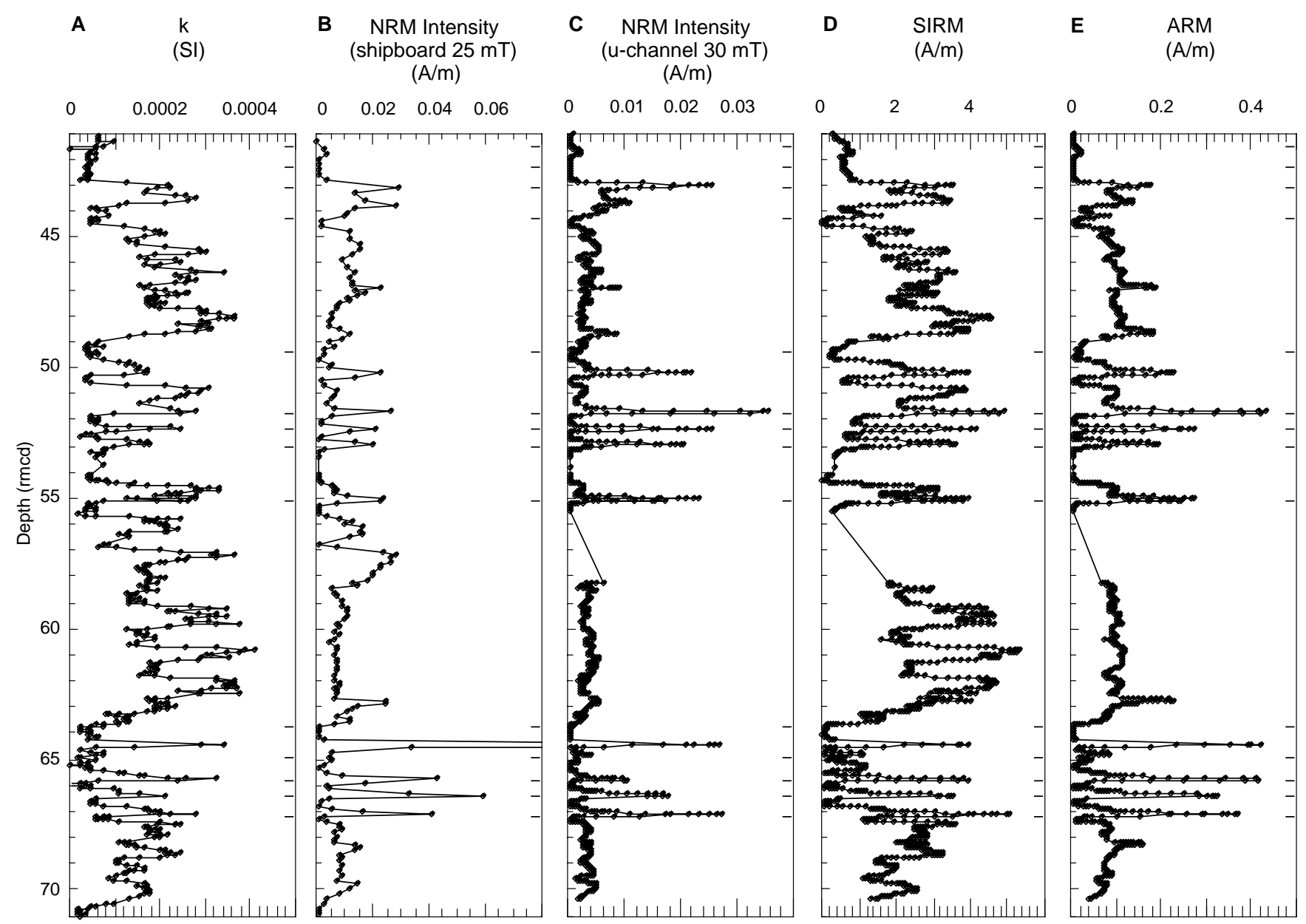

Figure 3. Shipboard and u-channel magnetic measurements for Hole 969B for the interval from 41 to 71 rmcd. Panels (A-E) are the same as for Figure 1. 


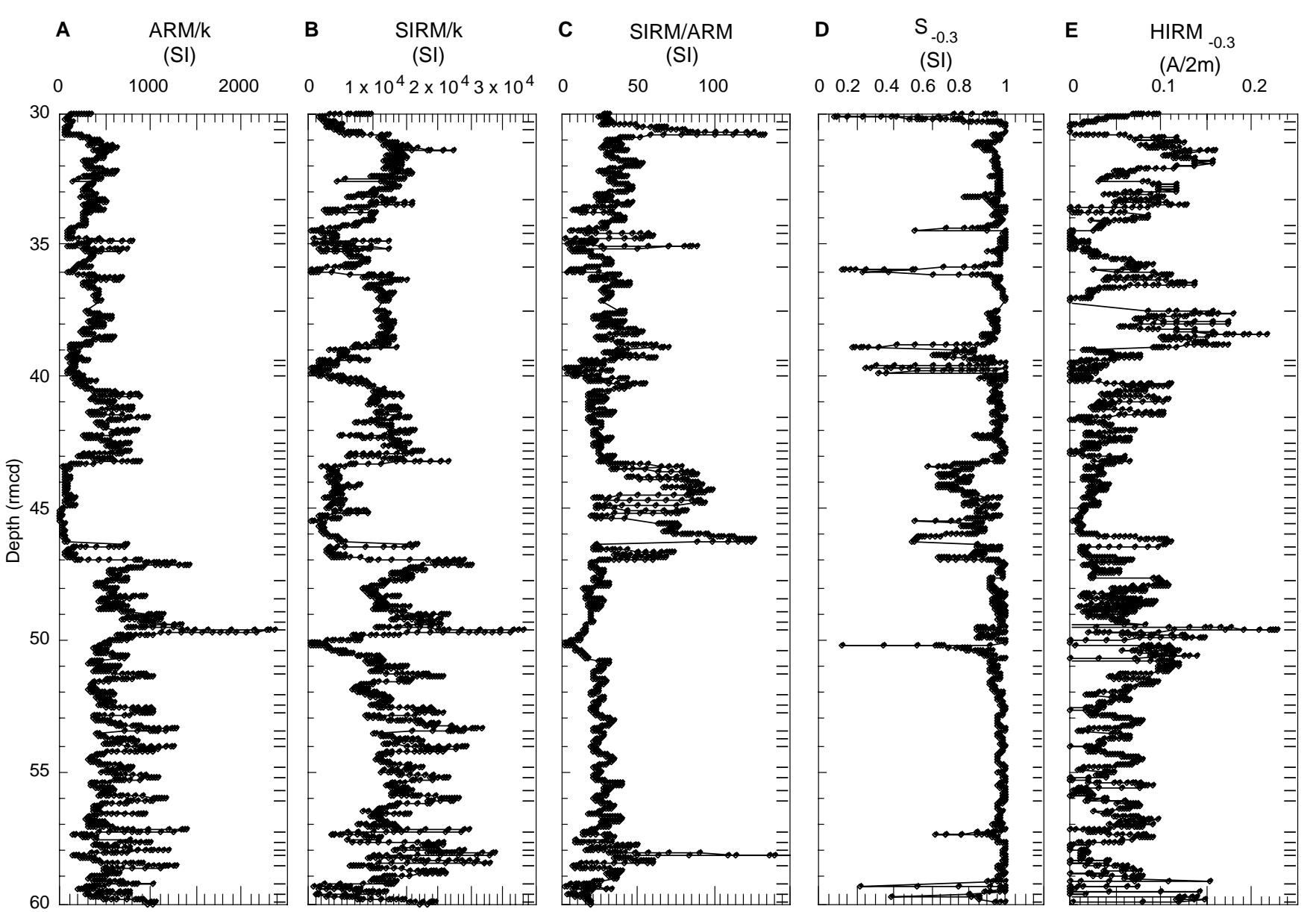

Figure 4. Constructed magnetic parameters from the composite sequence for Site 966 for the interval from 30 to 60 rmcd. A. Anhysteretic remanent magnetization (ARM) from u-channel samples divided by the volumetric magnetic susceptibility (k) from shipboard measurements of whole-cores, with interpolation to the same intervals as the corresponding u-channel measurements. B. Saturation isothermal remanent magnetization (SIRM) from u-channel samples divided by volumetric magnetic susceptibility (k) interpolated to 1-cm intervals. C. SIRM divided by ARM. D. S-ratio. E. "Hard" isothermal remanent magnetization (HIRM). Horizontal bars on the right-hand side of each figure indicate the position of sapropels, as identified from shipboard studies (Emeis, Robertson, Richter, et al., 1996). 


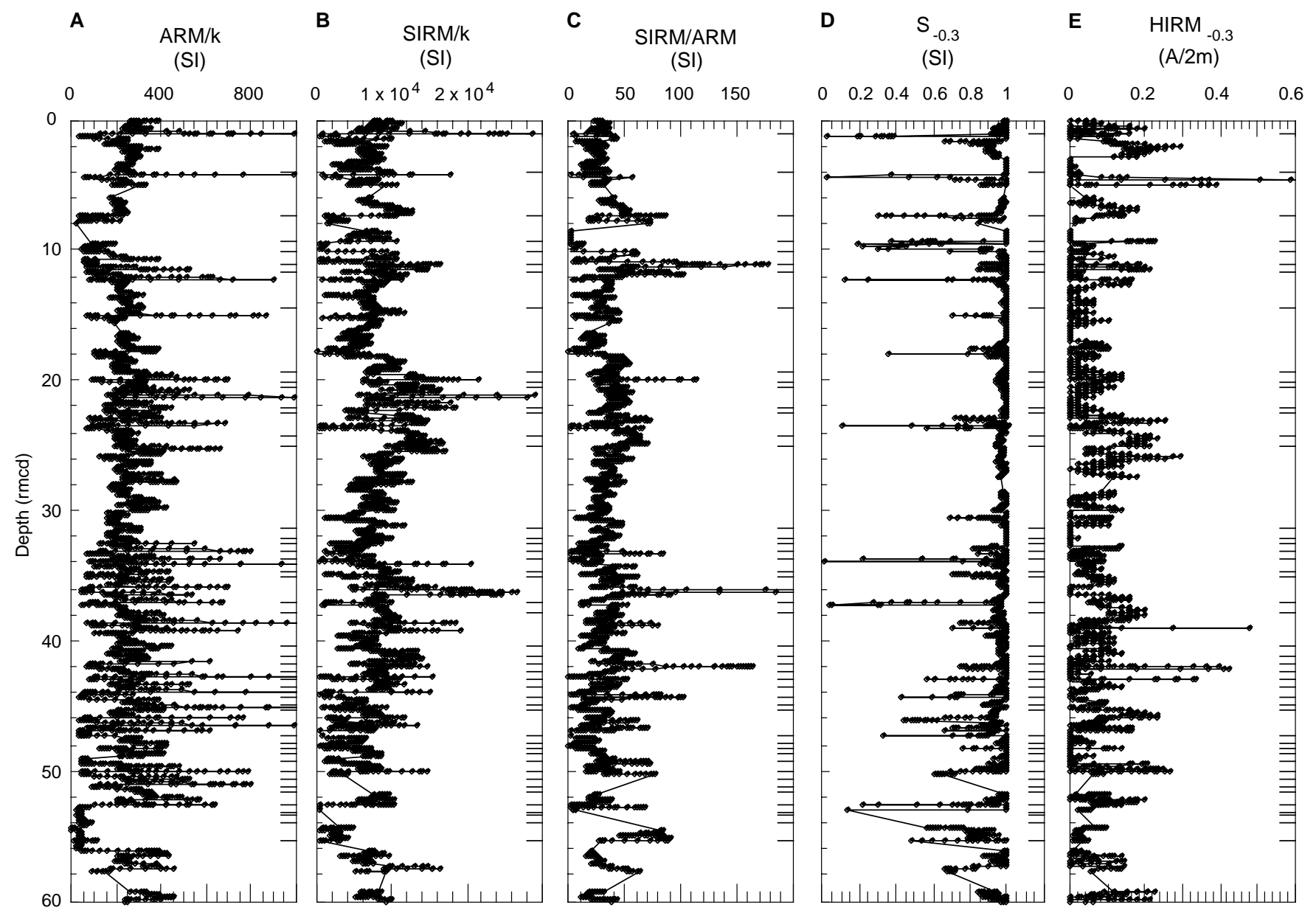

Figure 5. Constructed magnetic parameters from the composite sequence for Site 967 for the interval from 0 to 60 rmcd. Panels (A-E) are the same as for Figure 4 . 


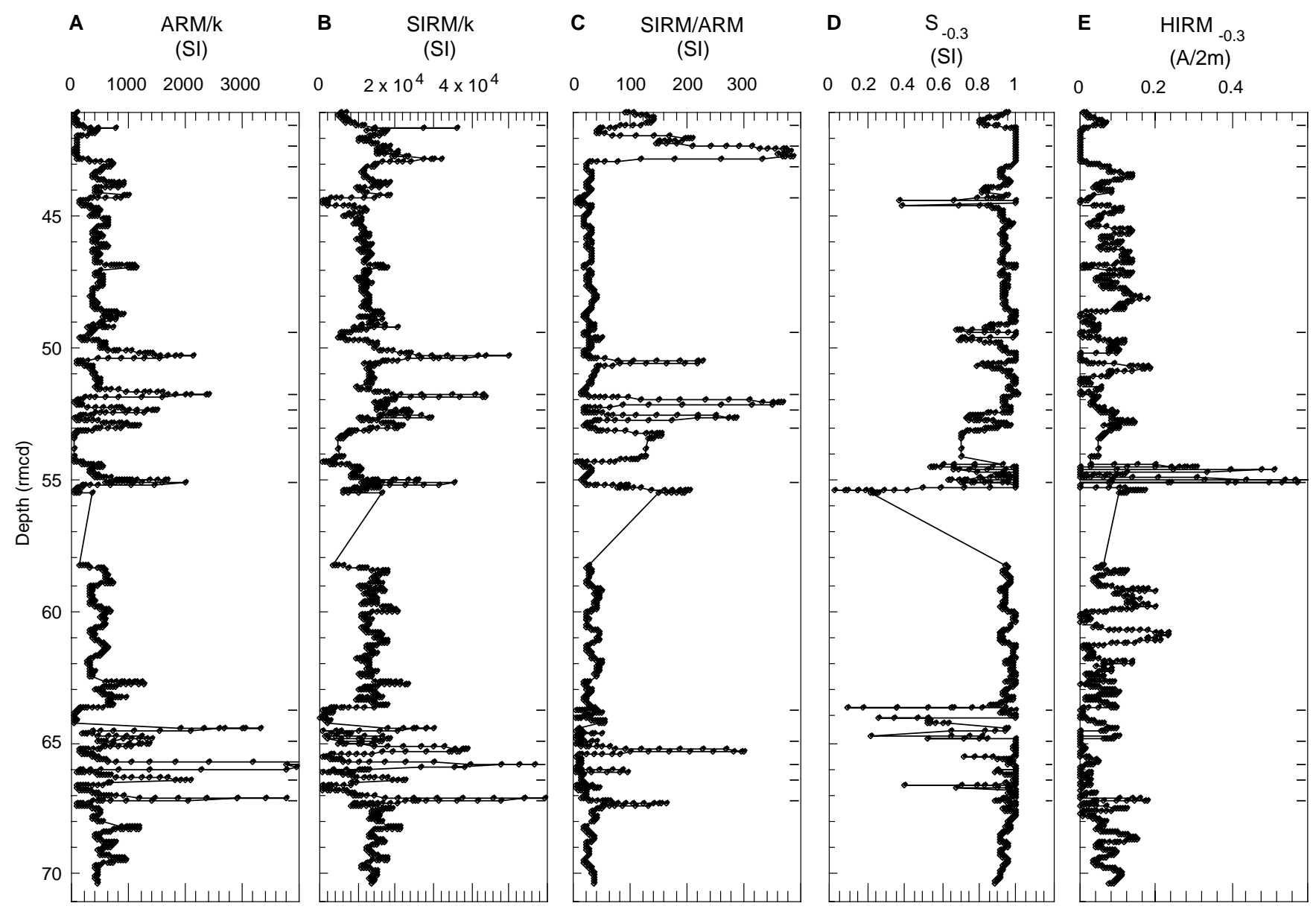

Figure 6. Constructed magnetic parameters from Hole $969 \mathrm{~B}$ for the interval from $\sim 41$ to $71 \mathrm{rmcd}$. Panels (A-E) are the same as for Figure 4. 